Reaction mechanisms and kinetics of the elimination processes of 2-chloroethylsilane and derivatives: A DFT study using CTST, RRKM, and BET theories

Peer-reviewed author version

SHIROUDI, Abolfazl; Zahedi, Ehsan; Oliaey, Ahmad Reza \& DELEUZE, Michael (2017) Reaction mechanisms and kinetics of the elimination processes of 2-chloroethylsilane and derivatives: A DFT study using CTST, RRKM, and BET theories. In: CHEMICAL PHYSICS, 485-486, p. 140-148.

DOI: 10.1016/j.chemphys.2017.01.009

Handle: http://hdl.handle.net/1942/23129 


\title{
Reaction mechanisms and kinetics of the elimination processes of 2-chloroethylsilane and derivatives: A DFT study using CTST, RRKM, and BET theories
}

\author{
Abolfazl Shiroudi $^{a *}$, Ehsan Zahedi $^{b}$, Ahmad Reza Oliaey $^{c}$, Michael S. Deleuze $^{d}$ \\ ${ }^{a}$ Young Researchers and Elite Club, East Tehran Branch, Islamic Azad University, Tehran, Iran \\ ${ }^{b}$ Chemistry Department, Shahrood Branch, Islamic Azad University, Shahrood, Iran \\ ${ }^{c}$ Chemistry Department, Tonekabon Branch, Islamic Azad University, Tonekabon, Iran \\ ${ }^{d}$ Center of Molecular and Materials Modelling, Hasselt University, Agoralaan, Gebouw D, B-3590 Diepenbeek, Belgium
}

\begin{abstract}
The thermal decomposition kinetics of 2-chloroethylsilane and derivatives in the gas phase has been studied computationally using density functional theory, along with various exchange-correlation functionals (UM06-2x and $\omega$ B97XD) and the aug-cc-pVTZ basis set. The calculated energy profile has been supplemented with calculations of kinetic rate constants under atmospheric pressure and in the fall-off regime, using transition state theory (TST) and statistical Rice-Ramsperger-Kassel-Marcus (RRKM) theory. Activation energies and rate constants obtained using the UM06-2x/aug-cc-pVTZ approach are in good agreement with the experimental data. The decomposition of 2-chloroethyltriethylsilane species into the related products $\left[\mathrm{C}_{2} \mathrm{H}_{4}+\mathrm{Et}_{3} \mathrm{SiCl}\right]$ is characterized by 6 successive structural stability domains associated to the sequence of catastrophes $\mathrm{C}_{8} \mathrm{H}_{19} \mathrm{SiCl}$ : $6-\mathrm{C}^{\dagger} \mathrm{FCC}{ }^{\dagger}[\mathrm{FF}]-0$ : $\mathrm{C}_{6} \mathrm{H}_{15} \mathrm{SiCl}+\mathrm{C}_{2} \mathrm{H}_{4}$. Breaking of $\mathrm{Si}-\mathrm{C}$ bonds and formation of $\mathrm{Si}-\mathrm{Cl}$ bonds occur in the vicinity of the transition state.
\end{abstract}

Keywords: Molecular modelling, energy barriers, 2-chloroethylsilane, elimination processes, rate constants, reaction mechanisms, electron localization function.

\footnotetext{
* Corresponding author: E-mail: abolfazl.shiroudi@uhasselt.be (A. Shiroudi)
} 


\section{Introduction}

The unusual reactivity of 2-chloroethylsilanes and its derivatives has been studied in the gas phase and in solution. It is well known that 2-chloroethylsilanes with three alkyl groups attached to the silicon atom decompose readily to ethylene and chlorosilane by heating, in such a manner that replacement of the alkyl groups by halogen leads to increasing the thermal stability [1-5]. The kinetics of the gas-phase thermal decomposition of 2-chloroethylsilanes and derivatives in a static system indicates that the elimination process predominates to form ethylene, and that the overall decomposition reaction is a first-order, homogenous, and apparently unimolecular $\beta$-elimination reaction [6].

Davidson et al. [1,7-9] have studied the kinetics of the gas-phase decomposition of 2-chloroethyltrichlorosilane [1], 2-chloroethylethyldichlorosilane [7], 2-chloroethyldiethylchlorosilane [8], and 2-chloroethyltriethylsilane [9] (see scheme 1). Sommer et al. [5] and Batuev et al. [3] have shown that 2-chloroethylsilane with three alkyl groups bonded to silicon decomposes easily when heated and that replacement of the alkyl groups by halogen increases the thermal stability. When the elimination of 2-chloroethylsilane proceeds by a concerted, four-center, and homolytic process, the replacement of a chlorine attached to silicon by an electron-supplying group would be expected to increase the rate constant, while when a quasi-heterolytic process was involved, the rate constant would also be affected by such a replacement [7]. It follows that the increase in rate constant caused by the replacement of one chlorine atom by an ethyl group is due mainly to a change in steric rather than electronic effects (Scheme 1).

Davidson et al. [1,7-9] have showed that the activation energies for the elimination of ethylene from 2-chloroethylsilane decrease when the attached chlorine atom to silicon is replaced by ethyl groups. They also suggested that this is evidence for some charge separation in the transition state, with the expanding of a partial positive charge on silicon. In the elimination reaction electron distribution at silicon atom of reactant and corresponding product are different due to the change from the $\mathrm{Si}-\mathrm{C}$ bond to a $\mathrm{Si}-\mathrm{Cl}$ bond, but it is not possible to estimate the size of this difference reliably [9]. 
<smiles>CC(Cl)CCl</smiles><smiles></smiles>

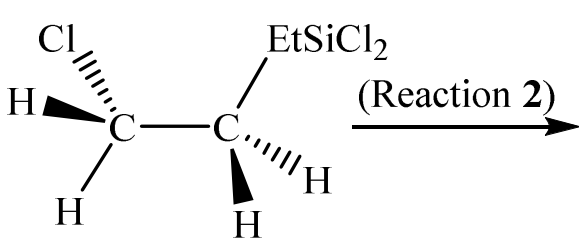<smiles>CC[C@H]1[SiH2][C@@H](Cl)[SiH](Cl)[C@@H]1Cl</smiles><smiles>CC[C@H](Cl)CCl</smiles><smiles>ClCCCCCCCCl</smiles><smiles>[CH][C@@H](C)[SiH2]C</smiles>

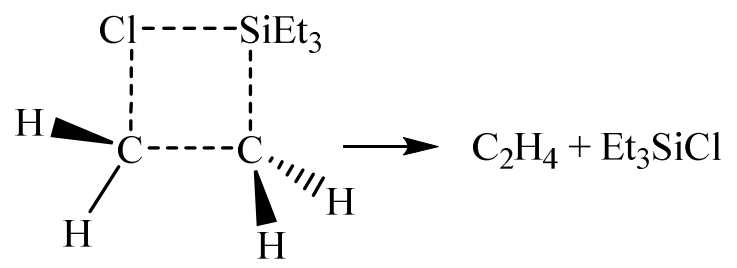

Scheme 1

An Arrhenius plot of all the kinetic unimolecular rate constants of the studied compounds that were measured or experimentally inferred over the temperature range $298-417^{\circ} \mathrm{C}$ is shown in Figure 1. Kinetic rate constant of the gas-phase unimolecular $\beta$ elimination processes of the compounds 1-4 exhibits positive temperature dependences over the studied temperature range, which is respectively equivalent to Arrhenius

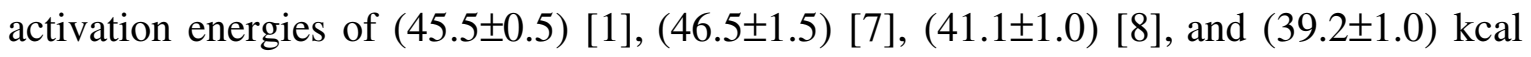
$\mathrm{mol}^{-1}$ [9] (see Figure 1). A least-square Arrhenius fit of the experimental data yields accordingly the following Arrhenius expression as follows [1,7-9]:

$$
\begin{aligned}
& k_{1}\left(\mathrm{~s}^{-1}\right)=10^{(11.40 \pm 0.16)} \exp \left(-\frac{45500 \pm 500}{R T}\right) ;\left[T=356-417^{\circ} \mathrm{C}\right] \\
& k_{2}\left(\mathrm{~s}^{-1}\right)=10^{(12.21 \pm 0.50)} \exp \left(-\frac{46500 \pm 1500}{R T}\right) ;\left[T=356-397^{\circ} \mathrm{C}\right] \\
& k_{3}\left(\mathrm{~s}^{-1}\right)=10^{(11.88 \pm 0.26)} \exp \left(-\frac{41100 \pm 1000}{R T}\right) ;\left[T=298-352^{\circ} \mathrm{C}\right] \\
& k_{4}\left(\mathrm{~s}^{-1}\right)=10^{(11.07 \pm 0.35)} \exp \left(-\frac{39200 \pm 1000}{R T}\right) ;\left[T=316-330^{\circ} \mathrm{C}\right]
\end{aligned}
$$


The above Arrhenius rate constants increases with increasing temperature at temperatures ranging from 298 to $417^{\circ} \mathrm{C}$, confirming positive activation energies.

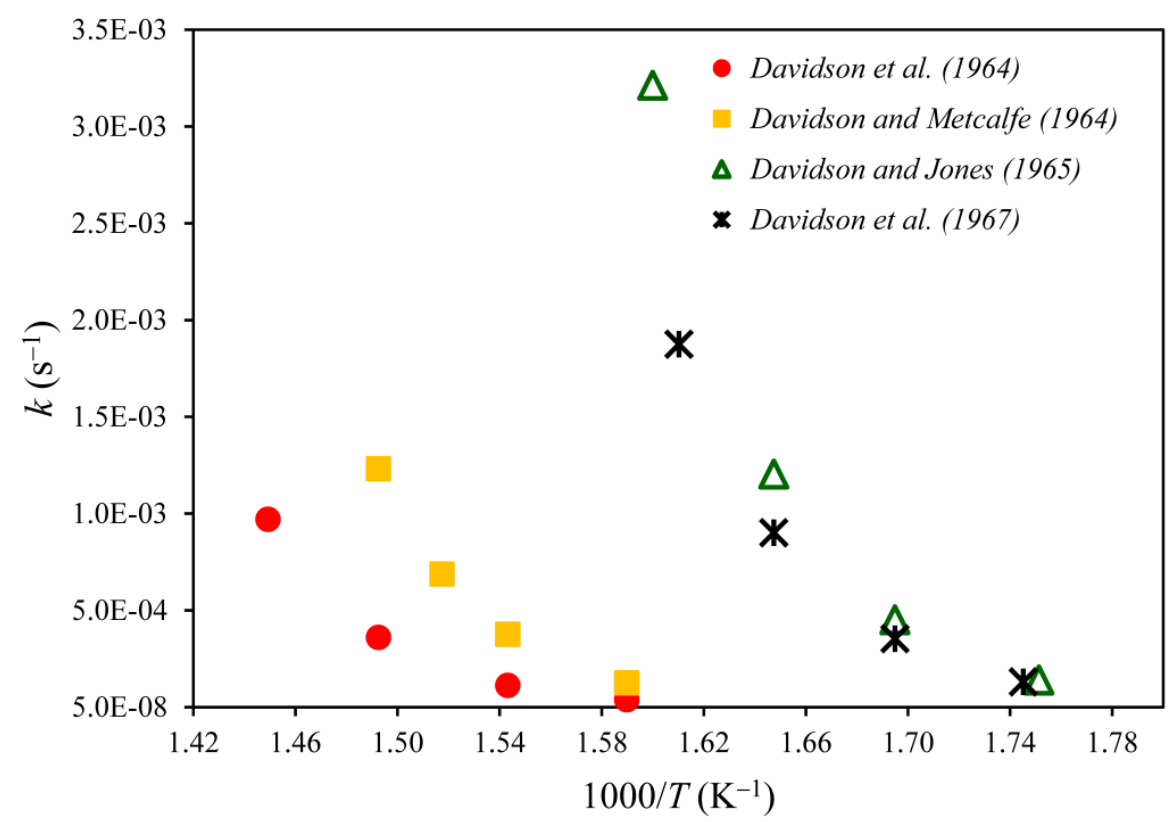

Figure 1. Arrhenius plot of the rate constant of the unimolecular $\beta$-elimination processes of the compounds 1-4. Legend: (๑) Davidson et al. [1]; (৫) Davidson and Metcalfe [7]; ( $\triangle$ ) Davidson and Jones [8]; (*) Davidson et al. [9].

In spite of the fact that the gas-phase reaction kinetics of the elimination processes of 2-chloroethylsilanes and its derivatives has been studied by Davidson et al. [1,7-9], the pressure dependence of the rate constants and molecular mechanisms of these reactions are unknown. The aim of study is to consider activation energies, kinetic rate constants as well as molecular mechanism of the thermal decomposition processes of 2chloroethylsilane and derivatives that are sketched in scheme 1. In this purpose, use shall be made of transition state theory (TST) [10-17], in conjunction with the dispersioncorrected $\omega \mathrm{B} 97 \mathrm{XD}[18]$ and the UM06-2x [19] exchange-correlation functionals and Dunning's augmented triple zeta correlation-consistent polarized core-valence basis sets (aug-cc-pVTZ) [20]. In addition, kinetic rate constants at the high pressure limit will be supplied using TST, and their falloff behavior at lower pressures will be studied using statistical Rice-Ramsperger-Kassel-Marcus (RRKM) theory [21-23], for the purpose of unraveling the detailed experiments by Davidson et al. [1,7-9] at temperature ranging from 298 to $471{ }^{\circ} \mathrm{C}$. Note that the UM06-2x functional has been especially designed both from the kinetic and thermodynamic viewpoint for accurate studies of chemical reactions. 
The aug-cc-pVTZ basis set is about twice as large as the $6-311+\mathrm{G}^{* *}$ basis set that was used in the previous study [24]. From the data obtained at the B3LYP/6-311+G ${ }^{* *}$ in this study can be compared with our newly supplied UM06- $2 x$ data. The obtained results in the previous study need to be verified using more reliable exchange-correlation functionals and basis set. Due to the self-interaction error of commonly used B3LYP functional [25], transition barriers obtained with the B3LYP energy functional are usually strongly underestimated [26,27].

\section{Computational details}

All the calculations were performed using the Gaussian 09 package of programs [28]. The molecular structures were visualized on the basis of the output data of the density functional theory (DFT) calculations using GaussView [29]. The structures of all stationary points have been optimized by using the DFT along with the $\omega \mathrm{B} 97 \mathrm{XD}$ and UM06-2x exchange-correlation functionals, in conjunction with diffuse functions (aug-cc-pVTZ basis set).

The corresponding calculations of harmonic vibrational frequencies at the same level of theory were then carried out in order to verify whether the stationary points are local minima or saddle points. For the possible transition state structures, the intrinsic reaction coordinate (IRC) approach have been used [30]. These calculations were carried out in both directions (forward and reverse) with 121 points at the UM06-2x/aug-cc-pVTZ level along the reaction path to check the connections between transition state structures and relevant minima.

Rate constants for the studied unimolecular reactions were investigated in the high pressure limit by means of transition state theory (TST) using UM06- $2 x$ level to estimate activation energies. The rationale for choosing the UM06- $2 x$ exchange-correlation functional is that a recent study by Zhao and Truhlar [19] has shown that it is the best one for studies involving main group thermochemistry, kinetics, noncovalent interactions, and electronic excitation energies to valence and Rydberg states. M06- $2 x$ exchange-correlation functional and its analogs are dedicated for precisely energetic considerations. However, recently it has been established that this approach overestimate activation parameters for elimination processes [31-33]. 
A computational study on the kinetics of unimolecular reactions can be determined by using a conventional transition state theory. The rate constants for decomposition reactions can be obtained as follows [34-36]:

$$
k_{\text {uni }}=\kappa(T) \frac{\sigma k_{\mathrm{B}} T}{h} \frac{Q_{\mathrm{TS}}^{\neq}(T)}{Q_{\mathrm{A}}(T)} \exp \left(-E_{a} / R T\right)
$$

where $k_{\mathrm{B}}, h$ and $R$ are the Boltzmann's, Planck's and ideal gas constants, respectively. In this equation, $\sigma$ denotes a symmetry number, and $\kappa(T)$ is the Wigner's tunneling correction factor [37].

$$
\kappa(T)=1+\frac{1}{24}\left(\frac{h \operatorname{Im}\left(v^{\neq}\right)}{k_{B} T}\right)^{2}
$$

where $\operatorname{Im}\left(v^{\ddagger}\right)$ is the imaginary vibrational frequency of the relevant transition state. Due to the simplicity of conventional TST, this method gives the upper limit of the kinetic rate constant, and enables to provide reliable rate constants in the limiting high-pressure behavior [23,38], especially important in the case of significant barrier heights.

In line with the temperatures at which the experiments by Davidson et al. [1,7-9] were conducted, unimolecular rate constants have been calculated for the temperature range $298-417{ }^{\circ} \mathrm{C}$ and pressure of 1.0 bar using conventional TST.

Note that, in practice, standard atmospheric pressures ( 1 bar) are usually considered to be large enough for reliably calculating rate constants using TST. The falloff behavior of canonical kinetic rate constants from the conventional TST limit $(P \rightarrow \infty)$ towards the low-pressure limit $(P \rightarrow 0)$ were also calculated with RRKM theory [21-23]. The microcanonical rate constants $k(E)$ are calculated using the well-known equation of RRKM theory [21]:

$$
k(E)=\frac{\sigma N^{\dagger}(E)}{h \rho(E)}
$$

where $N^{\dagger}(E)$ represents the total number of states at the transition state with energy less than or equal to $E$, and $\rho(E)$ is the density of states at the reactants [33]. The canonical rate constant $k(T)$ can be written as:

$$
k(T)=\frac{1}{Q(T)} \int k(E) N(E) \exp (-\beta E) d E
$$

where $\beta=(k T)^{-1}$ and $Q(T)$ is the internal state reactant partition function of the reactants.

All supplied TST and RRKM kinetic rate constants were performed using the Kinetic 
and Statistical Thermodynamical Package (KiSThelP) [39]. All these calculations rely upon UM06-2x/aug-cc-pVTZ predictions of ro-vibrational densities of states and activation energy barriers. Collisional stabilization rate constants were calculated using the Lennard-Jones (LJ) collision rate theory [40]. The strong collision approximation is used assuming that every collision deactivates with $\omega=\beta_{\mathrm{c}} \cdot Z_{\mathrm{LJ}} \cdot[\mathrm{M}]$ being the effective collision frequency where $\mathrm{Z}_{\mathrm{LJ}}$ is the Lennard-Jones collision frequency, $[\mathrm{M}]$ represents the total gas concentration, and $\beta_{\mathrm{c}}=0.2$ denotes the collisional efficiency. The collision frequencies $\left(Z_{\mathrm{LJ}}\right)$ are calculated by the $\mathrm{LJ}$ parameters: The retained $\mathrm{LJ}$ potential parameters for argon (as diluent gas) [38] and reactants 1-4 [41] are given as follows:

Table 1: Lennard-Jones (LJ) potential parameters

\begin{tabular}{lcc}
\hline \multirow{2}{*}{ Species } & \multicolumn{2}{c}{ LJ potential parameters } \\
\cline { 2 - 3 } & $\sigma(\AA)$ & $\varepsilon / k_{\mathrm{B}}(\mathrm{K})$ \\
\hline Argon (as diluent gas) & 3.465 & 113.5 \\
2-chloroethyltrichlorosilane (1) & 5.4 & 484.4 \\
2-chloroethylethyldichlorosilane (2) & 5.8 & 480.7 \\
2-chloroethyldiethylchlorosilane (3) & 6.1 & 477.9 \\
2-chloroethyltriethylsilane (4) & 6.4 & 475.9 \\
\hline
\end{tabular}

The bonding changes along the reaction pathway of the most favorable reaction $[R(4)$; 2-chloroethyltriethylsilane $\left.\rightarrow \mathrm{C}_{2} \mathrm{H}_{4}+\mathrm{Et}_{3} \mathrm{SiCl}\right]$ has been studied using bond evolution theory (BET) [42] in order to understand the breaking/forming bond process in the elimination reaction of 2-chloroethylsilanes. Bonding changes along reaction path can be studied from the characterization of the electron-density reorganization using bonding evolution theory, consisting of the joint use of Electron Localization Function (ELF) topology [43,44] and the catastrophe theory (CT) [45] as a new tool for the contemporary understanding of electronic rearrangements in chemical processes. The ELF topological analysis has been done with the TopMod program [46] and the Multiwfn suite of tools [47] using the M06$2 x /$ aug-cc-pVTZ monodeterminantal wavefunctions along the reaction coordinate to locate the successive structural stability domains (SSDs).

\section{Results and discussion}

\section{Energetic and thermodynamic parameters}

The reader is referred to Tables 2 and 3 for the total internal energies at $0 \mathrm{~K}$, as well as the enthalpies and Gibb's free energies at $298 \mathrm{~K}$ of all identified species along the 
chemical pathways. In line with experimental Arrhenius activation energies [1,7-9], all DFT calculations most clearly show that the gas-phase thermal decomposition of compound 1 is an endothermic process $\left(\Delta H \approx 0.7-0.9 \mathrm{kcal} \mathrm{mol}^{-1}\right)$ whereas the decomposition of compounds $\mathbf{2} \mathbf{- 4}$ is an exothermic process $(\Delta H \approx-3.4,-4.8$, and -10.0 kcal mol ${ }^{-1}$, respectively). All unimolecular $\beta$-elimination reactions 1-4 are exoergic processes $(\Delta G<0)$ at ambient temperature and pressure. From the energy profiles supplied in Table 2, the production of the $\mathrm{Et}_{3} \mathrm{SiCl}$ species is the most favored process among all products P1-P4, since the reaction pathway 4 is strongly exoergic $\left(\Delta G \approx-22 \mathrm{kcal} \mathrm{mol}^{-1}\right)$ and exothermic $\left(\Delta H \approx-10 \mathrm{kcal} \mathrm{mol}^{-1}\right)$.

The gas-phase unimolecular $\beta$-elimination processes of compounds $\mathbf{1 - 4}$ correspond to a concerted, four-center, and homolytic process. The replacement of a chlorine atom attached to silicon atom by an electron-supplying (ethyl) group is expected to decrease the activation energy and therefore the rate constant of the reaction pathway will be increased $[48,49]$.

Note that, the energy barrier height $\left(\Delta E_{0 \mathrm{~K}}^{\dagger}\right)$ for the reaction pathway 4 is lower by about 5.30-6.92 kcal mol $\mathrm{m}^{-1}$ than the barrier for pathway 1, which is consistent with the replacement of the three ethyl groups attached to silicon by chlorine atoms. Similar observations can be made when Gibb's free activation energies are considered: in spite of slightly unfavorable entropy effects, the Gibb's free energy for the 2-chloroethyltriethylsilane (compound 4) species $\left(41.06-44.41 \mathrm{kcal} \mathrm{mol}^{-1}\right.$ ) is lower than the ones for the 2-chloroethyltrichloro-silane (compound 1) species (48.49-50.28 kcal $\left.\mathrm{mol}^{-1}\right)$.

Indeed, the increase in the rate constant of dehydrochlorination is determined not only by the activation barrier, but also by the activation entropy $\left(\Delta S^{\dagger}\right)$ which is required to reach the transition state structure [7,50]. The positive activation entropy of reactant 4 compared with reactants 1-3 can be due to a greater charge separation and therefore a less restricted transition state for reactant $\mathbf{4}$, or may simply reflect greater restriction on rotations in the initial state of this compound [1,7-9]. In the elimination of ethylene from compounds 1-4, there will be of course a difference in electron distribution at silicon between compound $1\left(\mathrm{Cl}-\mathrm{C}_{2} \mathrm{H}_{4}-\mathrm{SiCl}_{3}\right)$ and compound $4\left(\mathrm{Cl}-\mathrm{C}_{2} \mathrm{H}_{4}-\mathrm{SiEt}_{3}\right)$ resulting from the change from a $\mathrm{Si}-\mathrm{C}$ bond to a $\mathrm{Si}-\mathrm{Cl}$ bond [9]. 
Table 2. Reaction energies, reaction enthalpies and Gibb's free reaction energies (in kcal $\mathrm{mol}^{-1}$ ) for the thermal decomposition of compounds 1-4 at different DFT levels of theory.

\begin{tabular}{|c|c|c|c|c|c|c|c|}
\hline \multirow[b]{2}{*}{ Reaction } & \multicolumn{3}{|c|}{$\omega B 97 X D / a u g-c c-p V T Z$} & \multicolumn{4}{|c|}{ UM06-2x/aug-cc-pVTZ } \\
\hline & $\Delta E_{0 \mathrm{~K}}$ & $\Delta H_{298 \mathrm{~K}}^{\circ}$ & $\Delta G_{298 \mathrm{~K}}^{\circ}$ & $\Delta E_{0 \mathrm{~K}}$ & $\Delta H_{298 \mathrm{~K}}^{\circ}$ & $\Delta G_{298 \mathrm{~K}}^{\circ}$ & $\Delta S_{298 \mathrm{~K}}^{\circ}$ \\
\hline 2-chloroethyltrichlorosilane $\rightarrow \mathrm{C}_{2} \mathrm{H}_{4}+\mathrm{SiCl}_{4}$ & -0.076 & 0.688 & -10.529 & 0.197 & $\begin{array}{c}0.917 \\
(-2.425)\end{array}$ & $\begin{array}{c}-10.131 \\
(-13.882)\end{array}$ & 37.057 \\
\hline 2-chloroethylethyldichlorosilane $\rightarrow \mathrm{C}_{2} \mathrm{H}_{4}+\mathrm{EtSiCl}_{3}$ & -3.741 & -3.414 & -13.688 & -3.899 & $\begin{array}{c}-3.031 \\
(-5.447)\end{array}$ & $\begin{array}{c}-15.129 \\
(-17.137)\end{array}$ & 40.578 \\
\hline 2-chloroethyldiethylchlorosilane $\rightarrow \mathrm{C}_{2} \mathrm{H}_{4}+\mathrm{Et}_{2} \mathrm{SiCl}_{2}$ & -5.489 & -4.742 & -15.891 & -5.622 & $\begin{array}{c}-4.777 \\
(-10.268)\end{array}$ & $\begin{array}{c}-16.832 \\
(-21.982)\end{array}$ & 40.437 \\
\hline 2-chloroethyltriethylsilane $\rightarrow \mathrm{C}_{2} \mathrm{H}_{4}+\mathrm{Et}_{3} \mathrm{SiCl}$ & -10.273 & -9.239 & -21.587 & -11.013 & $\begin{array}{c}-9.953 \\
(-14.407) \\
\end{array}$ & $\begin{array}{c}-22.426 \\
(-25.998) \\
\end{array}$ & 41.837 \\
\hline
\end{tabular}

- Ref. 24; The values in parentheses were calculated at the B3LYP/6-311++G* level of theory.

Table 3. Activation energies, enthalpies and Gibb's free activation energies (in kcal $\mathrm{mol}^{-1}$ ), and activation entropies (in cal $\mathrm{mol}^{-1} \mathrm{~K}^{-1}$ ) of transition states relative to the reactants along chemical pathways 1-4 at different DFT levels of theory ( $P=1 \mathrm{~atm})$.

\begin{tabular}{|c|c|c|c|c|c|c|c|c|}
\hline \multirow[b]{2}{*}{ Reaction } & \multicolumn{3}{|c|}{$\omega \mathrm{B} 97 \mathrm{XD} /$ aug-cc-pVTZ } & \multicolumn{4}{|c|}{ UM06-2x/aug-cc-pVTZ } & \multirow{2}{*}{$\begin{array}{l}\text { Experiment } \\
\left(\Delta E_{0 \mathrm{~K}}^{\dagger}\right)\end{array}$} \\
\hline & $\Delta E_{0 \mathrm{~K}}^{\dagger}$ & $\Delta H^{\circ}{ }_{298 \mathrm{~K}^{\dagger}}^{\dagger}$ & $\Delta G^{\circ}{ }_{298 \mathrm{~K}^{\dagger}}^{\dagger}$ & $\Delta E_{0 \mathrm{~K}}^{\dagger}$ & $\Delta H^{\circ}{ }_{298 \mathrm{~K}^{\dagger}}^{\dagger}$ & $\Delta G^{\circ}{ }_{298 \mathrm{~K}}^{\dagger}$ & $\Delta S^{\circ}{ }_{298 \mathrm{~K}}^{\dagger}$ & \\
\hline 2-chloroethyltrichlorosilane $\rightarrow \mathrm{TS} 1$ & 49.781 & 49.714 & 50.279 & $\begin{array}{c}47.908 \\
{[48.674]}\end{array}$ & $\begin{array}{c}47.782 \\
{[48.586]}\end{array}$ & $\begin{array}{c}48.490 \\
{[49.572]}\end{array}$ & $\begin{array}{c}-2.371 \\
(-8.0 \pm 0.7)^{a} \\
{[-3.308]}\end{array}$ & $(45.5 \pm 0.5)^{a}$ \\
\hline Imaginary frequency TS1 $\left(\mathrm{cm}^{-1}\right)$ & $421.86 i$ & & & $463.31 i$ & & & & \\
\hline 2-chloroethylethyldichlorosilane $\rightarrow \mathrm{TS} 2$ & 50.503 & 50.336 & 51.145 & $\begin{array}{c}48.030 \\
{[50.136]}\end{array}$ & $\begin{array}{c}47.852 \\
{[50.077]}\end{array}$ & $\begin{array}{c}48.598 \\
{[50.712]}\end{array}$ & $\begin{array}{c}-2.504 \\
(-3.6 \pm 2.0)^{b} \\
{[-2.128]}\end{array}$ & $(46.5 \pm 1.5)^{b}$ \\
\hline Imaginary frequency TS2 $\left(\mathrm{cm}^{-1}\right)$ & $469.85 i$ & & & $487.81 i$ & & & & \\
\hline 2-chloroethyldiethylchlorosilane $\rightarrow \mathrm{TS} 3$ & 49.652 & 49.496 & 50.448 & $\begin{array}{c}47.202 \\
{[47.504]}\end{array}$ & $\begin{array}{c}47.085 \\
{[47.409]}\end{array}$ & $\begin{array}{c}47.129 \\
{[48.529]}\end{array}$ & $\begin{array}{c}-0.147 \\
{[-3.754]}\end{array}$ & $41.1^{c}$ \\
\hline Imaginary frequency TS3 $\left(\mathrm{cm}^{-1}\right)$ & $458.40 i$ & & & $476.10 i$ & & & & \\
\hline 2-chloroethyltriethylsilane $\rightarrow \mathrm{TS} 4$ & 44.479 & 44.723 & 44.413 & $\begin{array}{c}40.988 \\
{[41.729]}\end{array}$ & $\begin{array}{c}41.191 \\
{[41.981]}\end{array}$ & $\begin{array}{c}41.063 \\
{[41.991]}\end{array}$ & $\begin{array}{c}+0.430 \\
{[-0.034]}\end{array}$ & $39.2^{d}$ \\
\hline Imaginary frequency TS4 $\left(\mathrm{cm}^{-1}\right)$ & $282.09 i$ & & & $238.15 i$ & & & & \\
\hline
\end{tabular}

- Experimental values: $a$ ) Ref [1]; $b$ ) Ref [7]; $c$ ) Ref [8]; $d$ ) Ref [9].

- Ref. 24; The values in square brackets were calculated at the B3LYP/6-311++G** level of theory.

Our best (UM06-2x) estimate for the activation energies are most generally in good agreement with the obtained results at the B3LYP/6-311+G ${ }^{* *}$ level of theory [24], and the largest discrepancy compare with this work amounts to $\sim 2.1 \mathrm{kcal} \mathrm{mol}^{-1}$ for the activation energy characterizing the decomposition reaction of compound $\mathbf{2}$ into the related products P2 $\left[\mathrm{C}_{2} \mathrm{H}_{4}+\mathrm{EtSiCl}_{3}\right]$ (see Table 3). A possible reason for this difference is that the 
6-311+G(2df,p) basis set may fail to quantitatively describe strong polarization effects. Indeed, it is worth reminding that the $6-311 \mathrm{G}$ basis set from which the $6-311+\mathrm{G}(2 \mathrm{df}, \mathrm{p})$ basis set derives is known to exhibit a too compact $2 p$ space [51], and to be effectively a basis set of double-zeta quality only in the $s$-space, due to improperly balanced expansion coefficients $[52,53]$.

\section{Kinetic parameters}

TST and RRKM unimolecular rate constants for the decomposition processes of the studied compounds were calculated in the gas-phase along with the UM06-2x/aug-ccpVTZ approach (Table 4) at a pressure of 1 bar and at the considered temperatures, in line with the original experiments [1,7-9]. Further RRKM data computed at lower and higher pressures are provided for the same temperatures in Tables $\mathrm{S} 1 a-\mathrm{S} 1 i$ of the Supporting Information. Theoretical values obtained at a pressure of 1 bar do not differ by more than one order of magnitude from the available experimental data [1,7-9].

Whatever the considered temperatures, the unimolecular rate constant for the formation of the $\mathrm{Et}_{3} \mathrm{SiCl}$ species is larger than that obtained for the $\mathrm{SiCl}_{4}, \mathrm{EtSiCl}_{3}$, and $\mathrm{Et}_{2} \mathrm{SiCl}_{2}$ species, which is in line with a reduction of the activation energy barrier by 6.92 , 7.04 , and $6.21 \mathrm{kcal} \mathrm{mol}^{-1}$, respectively on the corresponding chemical reaction pathways. Indeed, the obtained TST results (Table 4) indicate that kinetic rate constants for the 2-chloroethyltriethylsilane $\rightarrow \mathrm{C}_{2} \mathrm{H}_{4}+\mathrm{Et}_{3} \mathrm{SiCl}$ unimolecular reaction are larger than the rate constants obtained for the other elimination reaction pathways. As is to be expected, because of the involved positive energy barriers, these rate constants increase gradually with increasing temperatures.

An Arrhenius plot of the obtained unimolecular rate constants by means of RRKM theory for pathways $\mathbf{1 - 4}$, based on the UM06-2x energy profiles (see Figure 2) obviously confirms that the production of the $\mathrm{C}_{2} \mathrm{H}_{4}+\mathrm{Et} 3 \mathrm{SiCl}(\mathbf{P 4})$ species will be the fastest process under atmospheric pressure and at temperatures ranging from 298 to $417{ }^{\circ} \mathrm{C}$. The same observation holds for pressures ranging from $10^{-12}$ to $10^{2}$ bars (Tables S1a-S1e in the Supporting Information). Since the involved energy barriers are large, the formation of the $\mathrm{SiCl}_{4}, \mathrm{EtSiCl}_{3}$, and $\mathrm{Et}_{2} \mathrm{SiCl}_{2}$ species is characterized by lower rate constants at the considered temperatures, compared with the formation of the $\mathrm{Et}_{3} \mathrm{SiCl}$ species: the rate constants for these processes are smaller by at least 2-3 orders of magnitude than the rate constant characterizing the thermal decomposition of the 2-chloroethyltriethylsilane 
species into the $\mathrm{C}_{2} \mathrm{H}_{4}+\mathrm{Et}_{3} \mathrm{SiCl}$ one.

Table 4. Unimolecular rate constants $\left(\right.$ in $^{-1}$ ) for the reported reaction channels obtained by means of TST and RRKM theories ( $P=1$ bar), according to the computed UM06-2x/ aug-cc-pVTZ energy barriers.

\begin{tabular}{|c|c|c|c|c|c|c|c|c|c|}
\hline \multirow[b]{2}{*}{$T(\mathrm{~K})$} & \multirow[t]{2}{*}{ Pathway } & \multicolumn{4}{|c|}{ TST } & \multicolumn{4}{|c|}{ RRKM } \\
\hline & & $\begin{array}{c}\mathrm{R} 1 \rightarrow \mathrm{P} 1 \\
(\text { Reaction } \mathbf{1})\end{array}$ & $\begin{array}{c}\mathrm{R} 2 \rightarrow \mathrm{P} 2 \\
(\text { Reaction 2) }\end{array}$ & $\begin{array}{c}\mathrm{R} 3 \rightarrow \mathrm{P} 3 \\
(\text { Reaction 3) }\end{array}$ & $\begin{array}{c}\mathrm{R} 4 \rightarrow \mathrm{P} 4 \\
\text { (Reaction 4) }\end{array}$ & $\begin{array}{c}\mathrm{R} 1 \rightarrow \mathrm{P} 1 \\
(\text { Reaction } \mathbf{1})\end{array}$ & $\begin{array}{c}\mathrm{R} 2 \rightarrow \mathrm{P} 2 \\
(\text { Reaction 2) }\end{array}$ & $\begin{array}{c}\mathrm{R} 3 \rightarrow \mathrm{P} 3 \\
(\text { Reaction 3) }\end{array}$ & $\begin{array}{c}\mathrm{R} 4 \rightarrow \mathrm{P} 4 \\
\text { (Reaction 4) }\end{array}$ \\
\hline \multirow{2}{*}{\multicolumn{2}{|c|}{570}} & $7.05 \times 10^{-6}$ & $5.58 \times 10^{-6}$ & $3.09 \times 10^{-5}$ & $1.38 \times 10^{-2}$ & $6.78 \times 10^{-6}$ & $5.33 \times 10^{-6}$ & $2.95 \times 10^{-5}$ & $6.88 \times 10^{-3}$ \\
\hline & & $\left(8.97 \times 10^{-7}\right)^{a}$ & $\left(2.69 \times 10^{-6}\right)^{b}$ & $\left(1.09 \times 10^{-4}\right)^{c}$ & $\left(1.32 \times 10^{-4}\right)^{d}$ & $\left(8.97 \times 10^{-7}\right)^{a}$ & $\left(2.69 \times 10^{-6}\right)^{b}$ & $\left(1.09 \times 10^{-4}\right)^{c}$ & $\left(1.32 \times 10^{-4}\right)^{d}$ \\
\hline \multirow{2}{*}{\multicolumn{2}{|c|}{600}} & $5.67 \times 10^{-5}$ & $4.52 \times 10^{-5}$ & $2.43 \times 10^{-4}$ & $8.45 \times 10^{-2}$ & $5.48 \times 10^{-5}$ & $4.34 \times 10^{-5}$ & $2.34 \times 10^{-4}$ & $4.23 \times 10^{-2}$ \\
\hline & & $\left(6.69 \times 10^{-6}\right)^{a}$ & $\left(2.09 \times 10^{-5}\right)^{b}$ & $\left(6.17 \times 10^{-4}\right)^{c}$ & $\left(8.09 \times 10^{-4}\right)^{d}$ & $\left(6.69 \times 10^{-6}\right)^{a}$ & $\left(2.09 \times 10^{-5}\right)^{b}$ & $\left(6.17 \times 10^{-4}\right)^{c}$ & $\left(8.09 \times 10^{-4}\right)^{d}$ \\
\hline \multirow{2}{*}{\multicolumn{2}{|c|}{630}} & $3.75 \times 10^{-4}$ & $3.01 \times 10^{-4}$ & $1.58 \times 10^{-3}$ & $4.37 \times 10^{-1}$ & $3.64 \times 10^{-4}$ & $2.90 \times 10^{-4}$ & $1.52 \times 10^{-3}$ & $2.19 \times 10^{-1}$ \\
\hline & & $\left(4.12 \times 10^{-5}\right)^{a}$ & $\left(1.34 \times 10^{-4}\right)^{b}$ & $\left(2.95 \times 10^{-3}\right)^{c}$ & $\left(4.18 \times 10^{-3}\right)^{d}$ & $\left(4.12 \times 10^{-5}\right)^{a}$ & $\left(1.34 \times 10^{-4}\right)^{b}$ & $\left(2.95 \times 10^{-3}\right)^{c}$ & $\left(4.18 \times 10^{-3}\right)^{d}$ \\
\hline \multirow{2}{*}{\multicolumn{2}{|c|}{660}} & $2.09 \times 10^{-3}$ & $1.68 \times 10^{-3}$ & $8.62 \times 10^{-3}$ & $1.95 \times 10^{0}$ & $2.03 \times 10^{-3}$ & $1.63 \times 10^{-3}$ & $8.34 \times 10^{-3}$ & $9.74 \times 10^{-1}$ \\
\hline & & $\left(2.15 \times 10^{-4}\right)^{a}$ & $\left(7.26 \times 10^{-4}\right)^{b}$ & $\left(1.23 \times 10^{-2}\right)^{c}$ & $\left(1.86 \times 10^{-2}\right)^{d}$ & $\left(2.15 \times 10^{-4}\right)^{a}$ & $\left(7.26 \times 10^{-4}\right)^{b}$ & $\left(1.23 \times 10^{-2}\right)^{c}$ & $\left(1.86 \times 10^{-2}\right)^{d}$ \\
\hline \multirow{2}{*}{\multicolumn{2}{|c|}{690}} & $1.01 \times 10^{-2}$ & $8.13 \times 10^{-3}$ & $4.07 \times 10^{-2}$ & $7.62 \times 10^{0}$ & $9.80 \times 10^{-3}$ & $7.89 \times 10^{-3}$ & $3.95 \times 10^{-2}$ & $3.82 \times 10^{0}$ \\
\hline & & $\left(9.71 \times 10^{-4}\right)^{a}$ & $\left(3.39 \times 10^{-3}\right)^{b}$ & $\left(4.50 \times 10^{-2}\right)^{c}$ & $\left(7.26 \times 10^{-2}\right)^{d}$ & $\left(9.71 \times 10^{-4}\right)^{a}$ & $\left(3.39 \times 10^{-3}\right)^{b}$ & $\left(4.50 \times 10^{-2}\right)^{c}$ & $\left(7.26 \times 10^{-2}\right)^{d}$ \\
\hline
\end{tabular}

- Experimental values: $a$ ) $\operatorname{Ref}[1] ; b) \operatorname{Ref}[7] ; c) \operatorname{Ref}[8] ; d) \operatorname{Ref}[9]$.

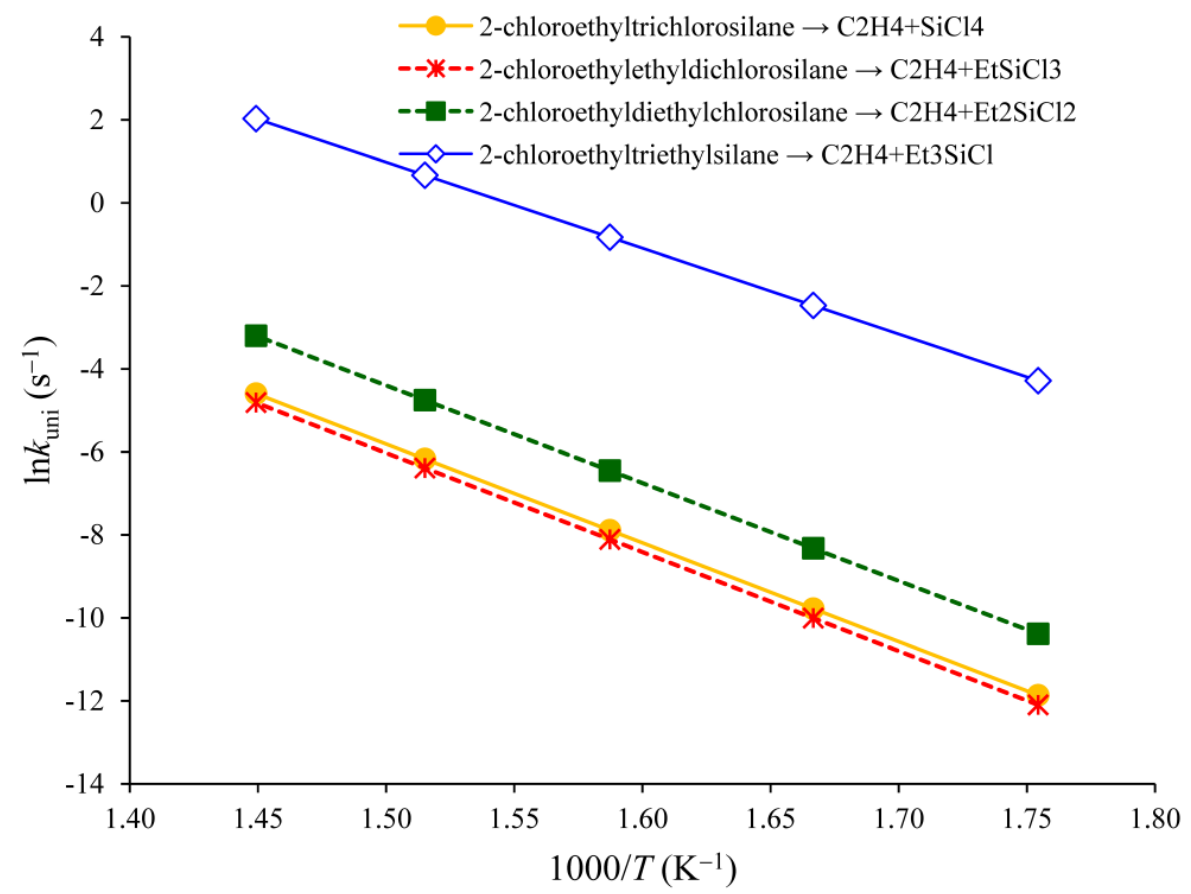

Figure 2. Arrhenius plot of the obtained TST unimolecular rate constants [for compounds 1-4] at the UM06-2x/aug-cc-pVTZ level of theory. $(P=1$ bar $)$

The reader is referred again to Figure 2 for an Arrhenius plot of the obtained RRKM estimates at a pressure of 1 bar for the decomposition processes of pathways 1-4, 
according to the UM06-2x/aug-cc-pVTZ estimates of energy barriers. This Figure clearly confirms that the production of the ethylene and 2-chloroethyltriethylsilane species (via pathway 4) is the faster process at all studied temperatures, and this down to extremely low pressures, larger than $10^{-12}$ bar. The same conclusion holds at much higher and lower pressures $\left(10^{-12}-10^{2}\right.$ bar) (Tables $\mathrm{S} 1 a-\mathrm{S} 1 e$ of the Supporting Information).

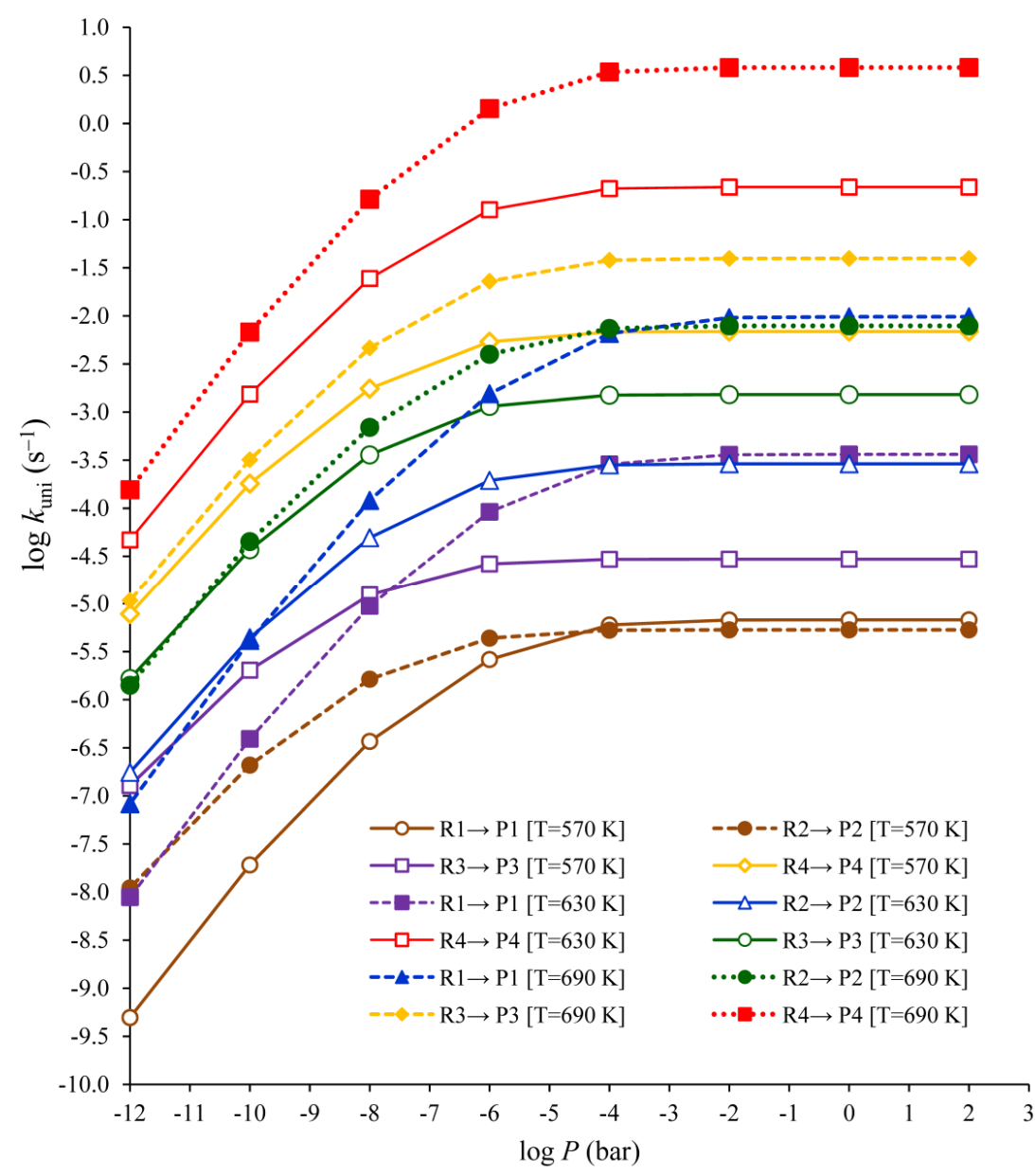

Figure 3. Pressure dependence of the unimolecular rate constants of the $\beta$-elimination processes of compounds 1-4 according to the UM06-2x/aug-cc-pVTZ energy profiles.

Inspection of Figure 3 and Table 4 shows that the RRKM unimolecular rate constants obtained for the reported chemical reaction pathways increase with increasing temperatures. Furthermore, upon inspecting the RRKM data displayed in Figure 3, it appears quite clearly that, in line with rather larger energy barriers, ranging from 41.98 to $47.91 \mathrm{kcal} \mathrm{mol}^{-1}$, pressures larger than $10^{-4}$ bar are in general sufficient for ensuring a saturation within $3 \%$ accuracy of the computed unimolecular kinetic rate constants compared with the high-pressure limit (TST) of the RRKM unimolecular rate constants. 
The comparison with the RRKM data nevertheless indicates that the TST approximation breaks down at pressures lower than $10^{-6}$ bar for the unimolecular rate constant characterizing pathway 4 [ $k_{\text {uni }}$ (4)] (i.e. 2-chloroethyltriethylsilane $\rightarrow \mathrm{C}_{2} \mathrm{H}_{4}+\mathrm{Et}_{3} \mathrm{SiCl}$ ), due to the strong positive activation energy $\left(40.98 \mathrm{kcal} \mathrm{mol}^{-1}\right)$ characterizing this reaction pathway. At a pressure of 1 bar, detailed inspection of Table 4 shows that ratios between the TST and RRKM estimates for this rate constant increases from $\sim 4.7$ to $\sim 18.2$ as the temperature increases from 298 to $471{ }^{\circ} \mathrm{C}$.

\section{Bonding evolution theory (BET) study of favorable unimolecular reaction}

Lewis type representation of bonding changes in different steps on the IRC path, as revealed from BET are graphically represented in Figure 4. The BET study of the elimination of ethylene from 2-chloroethyltriethylsilane indicates that this reaction along the intrinsic reaction coordinate can be topologically characterized by six differentiated structural stability domains (SSDs). The reaction path of the elimination processes is calculated by means of the IRC method and presented in Figure 5 with marked domains.

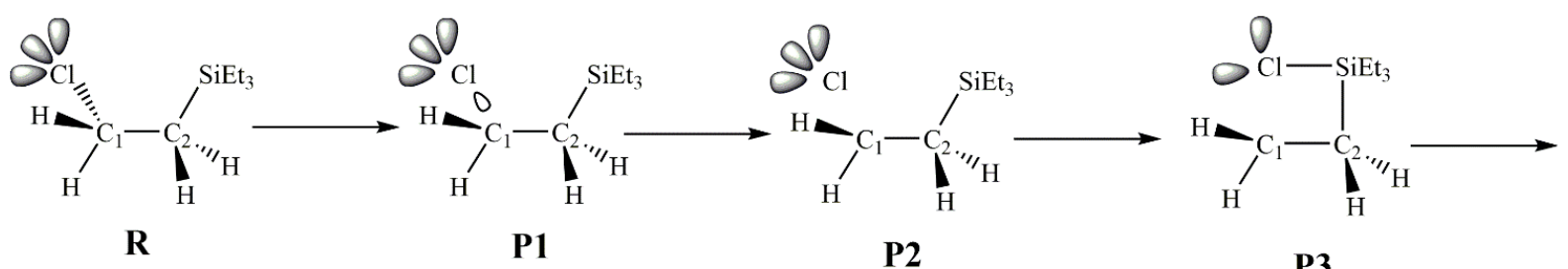

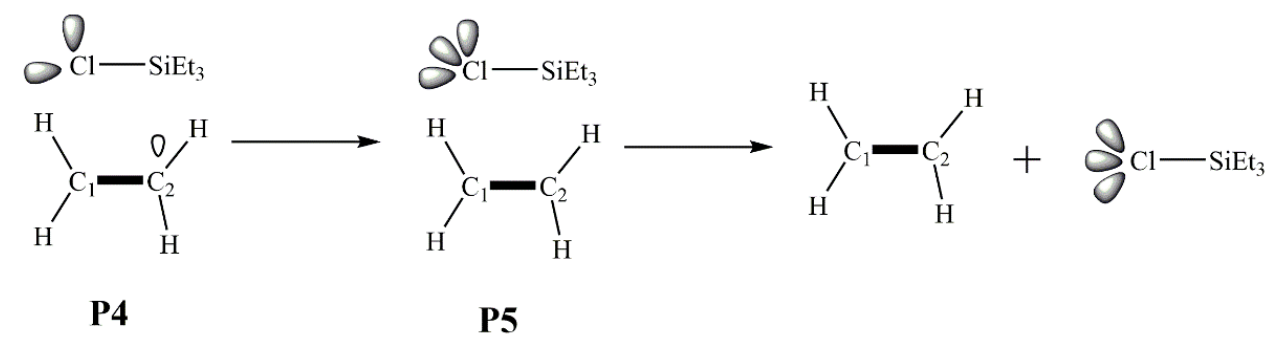

Figure 4. Lewis type representation of bonding changes for the elimination of ethylene from 2-chloroethyltriethylsilane based on the ELF topology. Filled lines indicate disynaptic basins with a population larger than $3.0 \mathrm{e}$. Large ellipses indicate lone electron pairs monosynaptic basins and small ellipses indicate non-bonding electron density with a population smaller than $1.0 \overline{\mathrm{e}}$.

The ELF basin populations for 2-chloroethyltriethylsilane, ethylene, $\mathrm{Et}_{3} \mathrm{SiCl}$ and the points $\mathrm{P} i(i=1-5)$ along the reaction coordinate between the SSDs are tabulated in Table 5. The SSD I, the most costly phase in term of energy with an increment of $29 \mathrm{kcal} \mathrm{mol}^{-1}$, begins at the level of 2-chloroethyltriethylsilane and ends before the P1 point, i.e. 
$\mathrm{R} x=-3.98829 \mathrm{amu}^{1 / 2}$ Bohr. The ELF analysis of 2-chloroethyltriethylsilane shows three disynaptic basins $\mathrm{V}\left(\mathrm{C}_{1}-\mathrm{Cl}\right), \mathrm{V}\left(\mathrm{C}_{1}-\mathrm{C}_{2}\right)$, and $\mathrm{V}\left(\mathrm{Si}-\mathrm{C}_{2}\right)$ corresponding to the $\mathrm{C}_{1}-\mathrm{Cl}$, $\mathrm{C}_{1}-\mathrm{C}_{2}$, and $\mathrm{Si}-\mathrm{C}_{2}$ single bonds whose electronic population integrates to $1.34,1.90$, and $2.05 \overline{\mathrm{e}}$, respectively; three disynaptic basins $\mathrm{V}\left(\mathrm{C}_{3}-\mathrm{C}_{4}\right), \mathrm{V}\left(\mathrm{C}_{5}-\mathrm{C}_{6}\right)$, and $\mathrm{V}\left(\mathrm{C}_{7}-\mathrm{C}_{8}\right)$ associated with the $\mathrm{C}_{3}-\mathrm{C}_{4}, \mathrm{C}_{5}-\mathrm{C}_{6}$, and $\mathrm{C}_{7}-\mathrm{C}_{8}$ single bonds integrating to $1.81 \overline{\mathrm{e}}$ each; three disynaptic basins $\mathrm{V}\left(\mathrm{Si}-\mathrm{C}_{3}\right), \mathrm{V}\left(\mathrm{Si}-\mathrm{C}_{5}\right)$, and $\mathrm{V}\left(\mathrm{Si}-\mathrm{C}_{7}\right)$ associated with the $\mathrm{Si}-\mathrm{C}_{3}$, $\mathrm{Si}-\mathrm{C}_{5}$, and $\mathrm{Si}-\mathrm{C}_{7}$ single bonds integrating to $2.06 \mathrm{e}$ each; and three monosynaptic basins $\mathrm{V}(\mathrm{Cl}), \mathrm{V}^{\prime}(\mathrm{Cl})$, and $\mathrm{V}^{\prime \prime}(\mathrm{Cl})$ corresponding to the lone pairs located on the $\mathrm{Cl}$ atom with total population of $6.42 \overline{\mathrm{e}}$. The SSD II starts at $\mathrm{R} x=-3.98829 \mathrm{amu}^{1 / 2}$ Bohr by the breaking of the covalent bond $\mathrm{C}_{1}-\mathrm{Cl}$ and formation of a pseudoradical center $\mathrm{V}^{\prime \prime \prime}(\mathrm{Cl})$ on the $\mathrm{Cl}$ atom with a population of $0.56 \mathrm{e}$. The SSD II ends before $\mathrm{R} x=-2.55914 \mathrm{amu}^{1 / 2} \mathrm{Bohr}$ and energy in this SSD increases by $9.13 \mathrm{kcal} \mathrm{mol}^{-1}$. The SSD III begins at $\mathrm{R} x=-2.55914$ $\mathrm{amu}^{1 / 2}$ Bohr by merging of the pseudoradical center generated in the previous SSD II into the lone pairs located at the $\mathrm{Cl}$ atom, and displacements of electron charge from the disynaptic basin $\mathrm{V}\left(\mathrm{Si}-\mathrm{C}_{2}\right)$ to the disynaptic basin $\mathrm{V}\left(\mathrm{C}_{1}-\mathrm{C}_{2}\right)$. The energy in SSD III increases by $3.70 \mathrm{kcal} \mathrm{mol}^{-1}$. The SSD IV starts at $\mathrm{R} x=-1.70165 \mathrm{amu}^{1 / 2} \mathrm{Bohr}$ by the disappearance of the monosynaptic basin $\mathrm{V}^{\prime \prime}(\mathrm{Cl})$ and appearance of the disynaptic basin $\mathrm{V}(\mathrm{Si}-\mathrm{Cl})$ associated to the formation of a new covalent bond $\mathrm{Si}-\mathrm{Cl}$ with an electron population equal to $0.94 \overline{\mathrm{e}}$. This SSD ends before the TS point with an increment of 2.54 $\mathrm{kcal} \mathrm{mol}^{-1}$ to reach the breaking of the covalent bond $\mathrm{Si}-\mathrm{C}_{2}$.

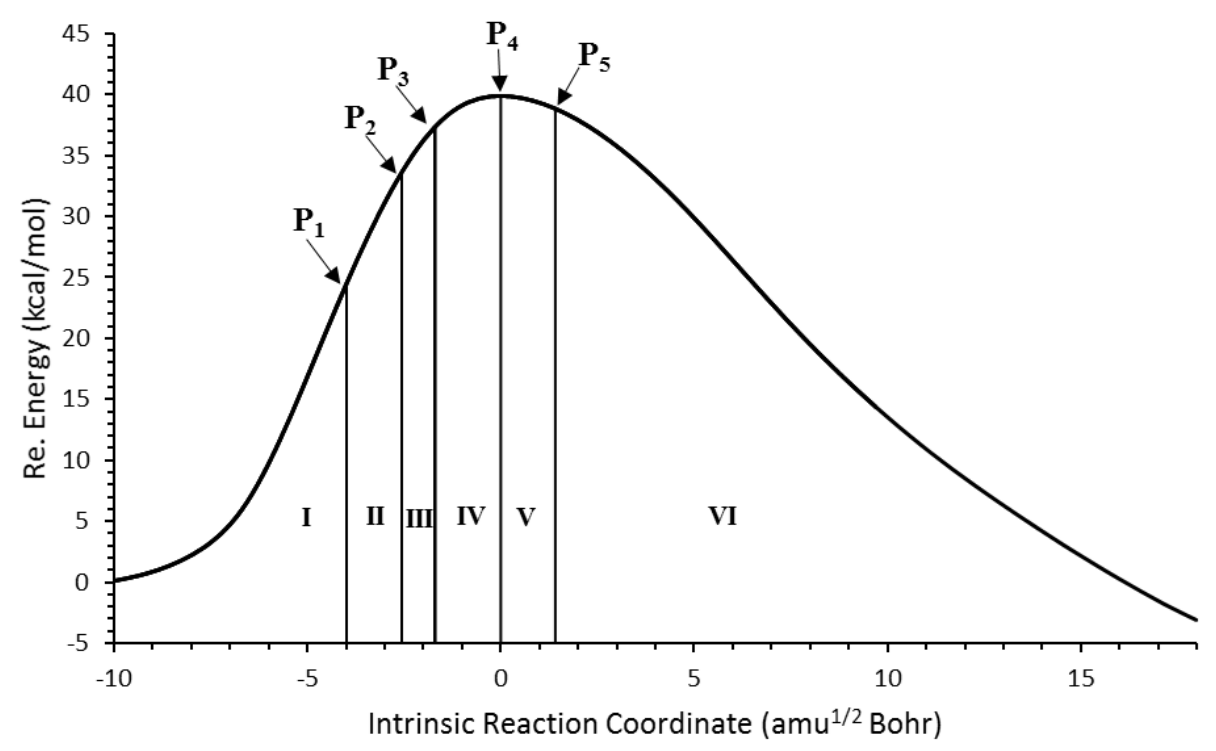


Figure 5. Energy profile for the elimination of ethylene from 2-chloroethyltriethylsilane calculated by means of the IRC method, with a step size of $0.1 \mathrm{amu}^{1 / 2}$ Bohr. The selected points on the IRC are considered for the ELF topological analysis.

The SSD $\mathbf{V}$ begins at the TS point by the disappearance of the disynaptic basin $\mathrm{V}$ $\left(\mathrm{Si}-\mathrm{C}_{2}\right)$ corresponding to the breaking of the covalent bond $\mathrm{Si}-\mathrm{C}_{2}$ and formation of new pseudoradical center on $\mathrm{C}_{2}$ atom with a population of $0.67 \overline{\mathrm{e}}$. The SSD V ends before $\mathrm{R} x=-1.40773 \mathrm{amu}^{1 / 2}$ Bohr. The SSD VI final turning point relates to the depopulation of monosynaptic basins $\mathrm{V}(\mathrm{Cl}), \mathrm{V}^{\prime}(\mathrm{Cl})$, and formation of monosynaptic basin $\mathrm{V}^{\prime \prime}(\mathrm{Cl})$ on $\mathrm{Cl}$ atom with an integrated population of $1.20 \overline{\mathrm{e}}$. Along the SSD VI ethylene detachment and consequently elimination process is completed. Color-filled maps of the ELF in the molecular plane defined by plane of the $\mathrm{Si}-\mathrm{Cl}-\mathrm{C}_{1}$ for 2-chloroethyltriethylsilane, and selected points defining the 6 SSDs characterizing the molecular mechanism of elimination process are presented in Figure 6. As can be seen the breaking of $\mathrm{C}_{1}-\mathrm{Cl}$ and $\mathrm{Si}-\mathrm{C}_{2}$ bonds starts at $\mathbf{P 1}$ and $\mathbf{P 4}$ points, respectively and their ELF values decreases continuously to approach to zero value at the end of the process. On the other hand, the formation of $\mathrm{Si}-\mathrm{Cl}$ bond starts at $\mathbf{P 3}$ points with ELF value 0.3. Elimination of ethylene from 2-chloroethyltriethylsilane can be characterized by 6 SSDs associated to the sequence of catastrophes $\mathrm{C}_{8} \mathrm{H}_{19} \mathrm{SiCl}$ : 6- $\mathrm{C}^{\dagger} \mathrm{FCC}^{\dagger}[\mathrm{FF}]-0$ : $\mathrm{C}_{6} \mathrm{H}_{15} \mathrm{SiCl}+\mathrm{C}_{2} \mathrm{H}_{4}$.

Table 5. Integrated electron populations of valence ELF basins for different points defining the 6 SSDs which characterize the molecular mechanism associated with the elimination of ethylene from 2-chloroethyltriethylsilane.

\begin{tabular}{|c|c|c|c|c|c|c|c|c|}
\hline & $\mathrm{R}$ & $\mathrm{P}_{1}$ & $\mathrm{P}_{2}$ & $\mathrm{P}_{3}$ & $\mathrm{P}_{4}(\mathrm{TS})$ & $\mathrm{P}_{5}$ & $\mathrm{C}_{2} \mathrm{H}_{4}$ & $\mathrm{Et}_{3} \mathrm{SiCl}$ \\
\hline $\mathrm{V}\left(\mathrm{C}_{1}-\mathrm{Cl}\right)$ & 1.34 & $\square$ & $\square$ & $\square$ & $\square$ & $\square$ & $\square$ & $\square$ \\
\hline $\mathrm{V}\left(\mathrm{C}_{1}-\mathrm{C}_{2}\right)$ & 1.90 & 2.16 & 2.37 & 2.51 & 3.1 & 3.46 & 1.64 & $\square$ \\
\hline $\mathrm{V}^{\prime}\left(\mathrm{C}_{1}-\mathrm{C}_{2}\right)$ & $\square$ & $\square$ & $\square$ & $\square$ & $\square$ & $\square$ & 1.74 & $\square$ \\
\hline $\mathrm{V}\left(\mathrm{C}_{3}-\mathrm{C}_{4}\right)$ & 1.81 & 1.82 & 1.82 & 1.82 & 1.81 & 1.80 & $\square$ & 1.81 \\
\hline $\mathrm{V}\left(\mathrm{C}_{5}-\mathrm{C}_{6}\right)$ & 1.81 & 1.80 & 1.80 & 1.80 & 1.79 & 1.79 & $\square$ & 1.81 \\
\hline $\mathrm{V}\left(\mathrm{C}_{7}-\mathrm{C}_{8}\right)$ & 1.81 & 1.80 & 1.80 & 1.80 & 1.79 & 1.79 & $\square$ & 1.81 \\
\hline $\mathrm{V}\left(\mathrm{Si}-\mathrm{C}_{2}\right)$ & 2.05 & 1.75 & 1.47 & 1.23 & $\square$ & $\square$ & $\square$ & $\square$ \\
\hline $\mathrm{V}\left(\mathrm{Si}-\mathrm{C}_{3}\right)$ & 2.06 & 2.05 & 2.04 & 2.03 & 2.02 & 2.03 & $\square$ & 2.06 \\
\hline $\mathrm{V}\left(\mathrm{Si}-\mathrm{C}_{5}\right)$ & 2.06 & 2.06 & 2.07 & 2.07 & 2.07 & 2.06 & $\square$ & 2.07 \\
\hline $\mathrm{V}\left(\mathrm{Si}-\mathrm{C}_{7}\right)$ & 2.06 & 2.06 & 2.07 & 2.07 & 2.07 & 2.07 & $\square$ & 2.07 \\
\hline $\mathrm{V}(\mathrm{Si}-\mathrm{Cl})$ & $\square$ & $\square$ & $\square$ & 0.94 & 1.01 & 1.06 & $\square$ & 1.55 \\
\hline $\mathrm{V}\left(\mathrm{C}_{2}\right)$ & $\square$ & $\square$ & $\square$ & $\square$ & 0.37 & $\square$ & $\square$ & $\square$ \\
\hline
\end{tabular}




\begin{tabular}{lcccccccc}
\hline $\mathrm{V}(\mathrm{Cl})$ & 2.22 & 2.92 & 3.18 & 3.28 & 3.36 & 2.78 & $\square$ & 2.46 \\
$\mathrm{~V}^{\prime}(\mathrm{Cl})$ & 2.27 & 2.93 & 3.25 & 3.34 & 3.50 & 2.86 & $\square$ & 2.49 \\
$\mathrm{~V}^{\prime \prime}(\mathrm{Cl})$ & 1.93 & 1.20 & 1.16 & $\square$ & $\square$ & 1.20 & $\square$ & 1.85 \\
$\mathrm{~V}^{\prime \prime \prime}(\mathrm{Cl})$ & $\square$ & 0.56 & $\square$ & $\square$ & $\square$ & $\square$ & $\square$ & $\square$ \\
\hline
\end{tabular}
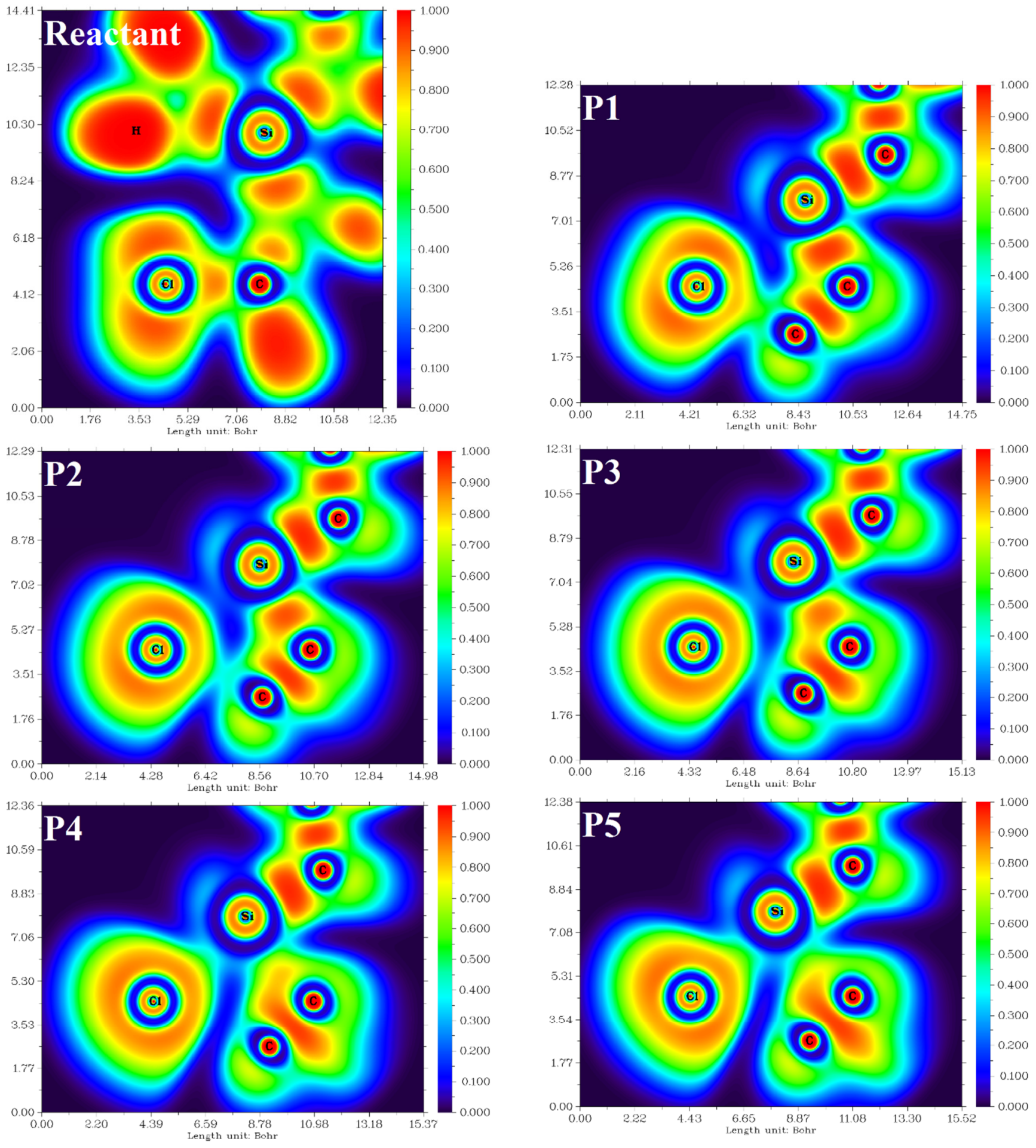

Figure 6. Color-filled maps of the electron localization function in the molecular plane defined by the $\mathrm{Si}-\mathrm{Cl}-\mathrm{C}_{1}$ atoms for reactant, at the selected points along the reaction coordinate for the elimination of ethylene from 2-chloroethyltriethylsilane. The ELF values [0 to 1] are mapped on a blue-green-red color 
scale indicated on the right of each representation. Blue and red colors indicate respectively no electron and high electron localization.

\section{Conclusion}

The thermal decomposition of 2-chloroethyltrichlorosilane (1), 2-chloroethylethyldichlorosilane (2), 2-chloroethyldiethylchlorosilane (3), and 2-chloroethyltriethylsilane (4) has been studied in the gas phase on computational grounds using density functional theory along with various exchange-correlation functionals $(\omega \mathrm{B} 97 \mathrm{XD}$, and UM06-2x) and the aug-cc-pVTZ basis set.

The calculated energy profiles have been supplemented with calculations of kinetic rate constants under atmospheric pressure and in the fall-off regime, down to pressure of $10^{-12}$ bar, using conventional TST and RRKM theories. Activation energies and rate constants obtained using the UM06-2x/aug-cc-pVTZ approach are in good agreement with the experimental data. RRKM calculations show that pressures larger than $10^{-4}$ bar are sufficient for ensuring the validity of the TST approximation for all studied reaction channels. The molecular mechanism of the most favorable reaction has been studied using the BET theory. BET analysis based on ELF topology indicates that the elimination of ethylene from 2-chloroethyltriethylsilane can be characterized by 6 SSDs associated to the sequence of catastrophes $\mathrm{C}_{8} \mathrm{H}_{19} \mathrm{SiCl}$ : 6- $\mathrm{C}^{\dagger} \mathrm{FCC}^{\dagger}[\mathrm{FF}]-0$ : $\mathrm{C}_{6} \mathrm{H}_{15} \mathrm{SiCl}+\mathrm{C}_{2} \mathrm{H}_{4}$.

\section{Supporting Information}

Supplementary data (Table S1) associated with this article can be found, in the online version. Table S1: Unimolecular rate constants for all reaction steps involved in the reported chemical pathways (results obtained by means of RRKM theory at different pressures and temperatures, according to the computed UM06-2x/aug-cc-pVTZ energy profiles).

\section{Acknowledgements}

All calculations presented in this work have been performed at the Flemish Supercomputer Center (Vlaams Supercomputer Centrum). This cluster has been financed by budgets obtained from the Katholieke Universiteit Leuven, as well as from individual contributions by users, and funding obtained from the Hercules foundation and the Flemish government. 


\section{References}

[1] I.M.T. Davidson, C. Eaborn, M.N. Lilly, Gas-phase reactions of halogenoalkylsilanes. Part I. 2-Chloroethyltrichlorosilane, J. Chem. Soc. (1964) 2624-2630.

[2] L.H. Sommer, F.C. Whitmore, Organo-silicon compounds. III. ${ }^{1} \alpha$ - and $\beta$-chloroalkyl silanes and the unusual reactivity of the $\operatorname{latter}^{2}$, J. Am. Chem. Soc. 68 (1946) $485-487$.

[3] M.I. Batuev, A.D. Petrov, V.A. Ponomarenko, A.D. Matveeva, J. Gen. Chem. (U.S.S.R) 26 (1965) 2613.

[4] L.H. Sommer, G.M. Baughman, Siliconium ions and carboniumions as reaction intermediates, J. Am. Chem. Soc. 83 (1961) 3346-3347.

[5] (a) L.H. Sommer, E. Dorfman, G.M. Goldberg, F.C. Whitmore, The reactivity with alkali of chlorine-carbon bonds alpha, beta and gamma to silicon ${ }^{1,2}$, J. Am. Chem. Soc. 68 (1946) 488-489; (b) L.H. Sommer, G.M. Goldberg, E. Dorfman, F.C. Whitmore, Organosilicon compounds. V. ${ }^{1} \beta$-eliminations involving silicon ${ }^{2}$, J. Am. Chem. Soc. 68 (1946) 1083-1085; (c) L.H. Sommer, D.L. Bailey, F.C. Whitmore, Further studies of $\beta$-eliminations involving silicon ${ }^{1}$, J. Am. Chem. Soc. 70 (1948) 2869-2872; (d) L.H. Sommer, D.L. Bailey, G.M. Goldberg, C.E. Buck, T.S. Bye, F.J. Evans, F.C. Whitmore, Vinylsilanes, chlorovinylsilanes and $\beta$-styryltrimethylsilane. Further studies on the $\alpha$-silicon effect and $\beta$-eliminations involving silicon ${ }^{1}$, J. Am. Chem. Soc. 76 (1954) 1613-1618.

[6] I.M.T. Davidson, Chem. Ind. (London) (1960) 1107.

[7] I.M.T. Davidson, C.J.L. Metcalfe, Gas-phase reactions of halogenoalkylsilanes. Part II. 2-Chloroethylethyldichlorosilane, J. Chem. Soc. (1964) 2630-2633.

[8] I.M.T. Davidson, M.R. Jones, Gas-phase reactions of halogenoalkylsilanes. Part III. 2-Chloroethyldiethylchlorosilane, J. Chem. Soc. (1965) 5481-5485.

[9] I.M.T. Davidson, M.R. Jones, C. Pett, Gas-phase reactions of halogenoalkylsilanes. Part IV. 1-Chloroethyldiethylchlorosilane and 2-chloroethyltrialkylsilanes, J. Chem. Soc. B (1967) 937-940.

[10] H. Eyring, The activated complex in chemical reactions, J. Chem. Phys. 3 (1935) $107-115$. 
[11] H.S. Johnston, Gas Phase Reaction Rate Theory, Roland Press, New York, 1966.

[12] K.J. Laidler, Theories of Chemical Reaction Rates, McGraw-Hill, New York, 1969.

[13] R.E. Weston, H.A. Schwartz, Chemical Kinetics, Prentice-Hall, New York, 1972.

[14] D. Rapp, Statistical Mechanics, Holt, Rinehart, and Winston, New York, 1972.

[15] E.E. Nikitin, Theory of Elementary Atomic and Molecular Processes in Gases, Clarendon Press, Oxford, 1974.

[16] I.W.M. Smith, Kinetics and Dynamics of Elementary Gas Reactions, Butterworths, London, 1980.

[17] A.E. Reed, L.A. Curtiss, F. Weinhold, Intermolecular interactions from a natural bond orbital, donor-acceptor viewpoint, Chem. Rev. 88 (1988) 899-926.

[18] J.D. Chai, M. Head-Gordon, Long-range corrected hybrid density functionals with damped atom-atom dispersion corrections, Phys. Chem. Chem. Phys. 10 (2008) $6615-6620$.

[19] Y. Zhao, D.G. Truhlar, The M06 suite of density functionals for main group thermochemistry, thermochemical kinetics, noncovalent interactions, excited states, and transition elements: Two new functionals and systematic testing of four M06class functionals and 12 other functionals, Theor. Chem. Acc. 120 (2008) 215-241.

[20] T.H. Dunning Jr., Gaussian basis sets for use in correlated molecular calculations. I. The atoms boron through neon and hydrogen, J. Chem. Phys. 90 (1989) 1007-1023

[21] P.J. Robinson, K.A. Holbrook, Unimolecular Reactions, Wiley, New York, 1972.

[22] J.I. Steinfeld, J.S. Francisco, W.L. Hase, Chemical Kinetics and Dynamics. PrenticeHall, Englewood Cliffs, New Jersey, 1999.

[23] H. Eyring, S.H. Lin, S.M. Lin, Basic Chemical Kinetics, Wiley, New York, 1980.

[24] A. Shiroudi, E. Zahedi, Theoretical study and NBO analysis on the gas phase elimination kinetics mechanism of 2-chloroethylsilane and derivatives, Prog. React. Kinet. Mec. 37 (2012) 76-89.

[25] J.P. Perdew, A. Zunger, From sulfoxide precursors to model oligomers of conducting polymers. Phys. Rev. B 23 (1981) 5048-5079.

[26] L. Claes, J.-P. François, M.S. Deleuze, Theoretical study of the internal elimination reactions of xanthate precursors, J. Am. Chem. Soc. 124 (2002) 7563-7572.

[27] L. Claes, J.-P. François, M.S. Deleuze, Self-interaction correction to densityfunctional approximations for many-electron systems, J. Comp. Chem. 24 (2003) 2023-2031. 
[28] M.J. Frisch, G.W. Trucks, H.B. Schlegel, G.E. Scuseria, M.A. Robb, J.R. Cheeseman, G. Scalmani, V. Barone, B. Mennucci, G.A. Petersson, H. Nakatsuji, M. Caricato, X. Li, H.P. Hratchian, A.F. Izmaylov, J. Bloino, G. Zheng, J.L. Sonnenberg, M. Hada, M. Ehara, K. Toyota, R. Fukuda, J. Hasegawa, M. Ishida, T. Nakajima, Y. Honda, O. Kitao, H. Nakai, T. Vreven, J.A. Montgomery Jr., J.E. Peralta, F. Ogliaro, M. Bearpark, J.J. Heyd, E. Brothers, K.N. Kudin, V.N. Staroverov, R. Kobayashi, J. Normand, K. Raghavachari, A. Rendell, J.C. Burant, S.S. Iyengar, J. Tomasi, M. Cossi, N. Rega, J. M. Millam, M. Klene, J.E. Knox, J.B. Cross, V. Bakken, C. Adamo, J. Jaramillo, R. Gomperts, R.E. Stratmann, O. Yazyev, A.J. Austin, R. Cammi, C. Pomelli, J.W. Ochterski, R.L. Martin, K. Morokuma, V.G. Zakrzewski, G.A. Voth, P. Salvador, J.J. Dannenberg, S. Dapprich, A.D. Daniels, O. Farkas, J.B. Foresman, J.V. Ortiz, J. Cioslowski, D.J. Fox, Gaussian 09 Inc, Wallingford, CT, USA, Gaussian Inc., Wallingford CT, 2009.

[29] R. Dennington II, T. Keith, J. Millam, K. Eppinnett, W.L. Hovell, R. Gilliland, GaussView, Version 5.0; Semichem, Inc.: Shawnee Mission, KS, 2003.

[30] (a) C. Gonzalez, H.B. Schlegel, An improved algorithm for reaction path following, J. Chem. Phys. 90 (1989) 2154-2161; (b) C. Gonzalez, H.B. Schlegel, Reaction path following in mass-weighted internal coordinates, J. Phys. Chem. 94 (1990) $5523-5527$.

[31] R. Jasiński, Searching for zwitterionic intermediates in hetero Diels-Alder reactions between methyl $\alpha, p$-dinitrocinnamate and vinyl-alkyl ethers, Comp. Theor. Chem. 1046 (2014) 93-98.

[32] R. Jasiński, Molecular mechanism of thermal decomposition of fluoronitroazoxy compounds: DFT computational study, J. Fluor. Chem. 160 (2014) 29-33.

[33] A. Shiroudi, E. Zahedi, Understanding the kinetics of thermal decomposition of 2,3epoxy-2,3-dimethylbutane using RRKM theory, RSC. Adv. 6 (2016) 91882-91892.

[34] R. Chang, Physical Chemistry for the Biosciences, University Science Books, Sausalito, California, 2005.

[35] J.W. Moore, R.G. Pearson, Kinetics and Mechanism-The Study of Homogeneous Chemical Reactions, Wiley, New York, 1981.

[36] H.H. Carstensen, A.M. Dean, O. Deutschmann, Rate constants for the $\mathrm{H}$ abstraction from alkanes $(\mathrm{R}-\mathrm{H})$ by $\mathrm{R}^{\prime} \mathrm{O}_{2}$ radicals: A systematic study on the impact of $\mathrm{R}$ and $\mathrm{R}^{\prime}$, Proc. Combust. Inst. 31 (2007) 149-157. 
[37] (a) E. Wigner, Calculation of the rate of elementary association reactions, J. Chem. Phys. 5 (1937) 720-725; (b) E. Wigner, Uber das uberschreiten von potentialschwellen bei chemischen reaktionen, Z. Phys. Chem. B 19 (1932) 203-216.

[38] F.M. Mourits, H.A. Rummens, A critical evaluation of Lennard-Jones and stockmayer potential parameters and of some correlation methods, Can J. Chem. 55 (1977) 3007-3020.

[39] S. Canneaux, F. Bohr, E. Henon, KiSThelP: A program to predict thermodynamic properties and rate constants from quantum chemistry results, J. Comput. Chem. 35 (2014) 82-93.

[40] J. Troe, Theory of thermal unimolecular reactions at low pressures. II. Strong collision rate constants: applications, J. Chem. Phys. 66 (1977) 4758-4775.

[41] R.J. Kee, F.M. Rupley, J.A. Miller, M.E. Coltrin, J.F. Grcar, E. Meeks, H.K. Moffat, A.E. Lutz, G. Dixon-Lewis, M.D. Smooke, J. Warnatz, G.H. Evans, R.S. Larson, R.E. Mitchell, L.R. Petzold, W.C. Reynolds, M. Caracotsios, W.E. Stewart, P. Glarborg, C. Wang, C.L. McLellan, O. Adigun, W.G. Houf, C.P. Chou, S.F. Miller, P. Ho, P.D. Young, D.J. Young, D.W. Hodgson, M.V. Petrova, K.V. Puduppakkam, CHEMKIN, Reaction Design, San Diego, CA, 2010.

[42] X. Krokidis, S. Noury, B. Silvi, Characterization of elementary chemical processes by catastrophe theory, J. Phys. Chem. A 101 (1997) 7277-7282.

[43] A.D. Becke, K.E. Edgecombe, A simple measure of electron localization in atomic and molecular systems, J. Chem. Phys. 92 (1990) 5397-5403.

[44] B. Silvi, A. Savin, Classification of chemical bonds based on topological analysis of electron localization functions, Nature 371 (1994) 683-686.

[45] R. Thom, Stabilite Structurelle et Morphogenese, Essai d'une Theorie Generale des Modeles, InterEditions, Paris, 1977.

[46] S. Noury, X. Krokidis, F. Fuster, B. Silvi, TopMod Package, Paris, 1997.

[47] T. Lu, F. Chen, Multiwfn: A multifunctional wavefunction analyser, J. Comput. Chem. 33 (2012) 580-592.

[48] A. Maccoll, Gas-phase eliminations. Part I. The unimolecular gas-phase pyrolysis of some esters and analogous compounds, J. Chem. Soc. (1958) 3398-3402.

[49] C. Eaborn, Organosilicon Compounds, Butterworths Scientific Publications, London, 1960. 
[50] W. Sun, L. Yang, L. Yu, M. Saeys, Ab initio reaction path analysis for the initial hydrogen abstraction from organic acids by hydroxyl radicals, J. Phys. Chem. A 113 (2009) 7852-7860.

[51] G.E. Scuseria, H.F. Schaefer III, The photodissociation of formaldehyde: a coupled cluster study including connected triple excitations of the transition state barrier height for $\mathrm{H}_{2} \mathrm{CO} \rightarrow \mathrm{H}_{2}+\mathrm{CO}$, J. Chem. Phys. 90 (1989) 3629-3636.

[52] R.S. Grev, H.F. Schaefer III, 6-311G is not of valence triple-zeta quality, J. Chem. Phys. 91 (1989) 7305-7306.

[53] A. Shiroudi, M.S. Deleuze, Reaction mechanisms and kinetics of the isomerization processes of naphthalene peroxy radicals, Comput. Theor. Chem. 1074 (2015) $26-35$. 